\title{
IN MEMORIAM CARL OTTO SEGERDAHL
}

Carl Otto Segerdahl joined the first circle of disciples around Harald Cramér in the early I930s. Segerdahl soon attracted the attention of Cramér, who found him a promising student with an inquiring turn of mind enthusiastically tackling problems that came up in courses of lectures and seminars. Having rapidly completed his studies while engaged in a great many other tasks, he passed his licentiate examination and joined the Thule Life Insurance Company in 1935, becoming its responsible actuary in I940, while he was also engaged in a qualified work as a cryptanalyst of the Swedish National Defence.

In 1939 Segerdahl defended his doctoral dissertation "On homogeneous random processes and collective risk theory". With his mathematical wit, Segerdahl had been captivated by Cramér's presentation of collective risk theory, developed in Cramér's work from I930 in Skandia's 75th Anniversary Publication. Cramér had already in I926 shown a keen interest in Lundberg's abstruse work by an exhaustive penetration of the risk theory in a review for the Scandinavian Actuarial Journal of works published in Swedish by Filip Lundberg in I926 and earlier. Cramér's works inspired already in the early r930s Fredrik Esscher and other Swedish actuaries to write a number of essays on collective risk theory.

These works on risk theory happened to appear at about the same time but independently of Kolmogoroff's and Khintchine's famous volumes on stochastic processes published in I93I and in I933. Thanks to these works, it became possible at this time to fit collective risk theory into the general theory of stochastic processes. Cramér developed and supported such a general presentation of risk theory, and Segerdahl presented his dissertation in this very spirit.

In his dissertation Segerdahl applied mathematical rigour to derive theorems on ruin probability which Filip Lundberg arrived at by an intuitive approach. Thus, Segerdahl was a pioneer in applying the general theory of discontinuous stochastic processes with independent and stationary increments to risk processes. As Grenander, his predecessor in the chair, observed in his expert report on 
Segerdahl's appointment, the dissertation attracted great attention and even now, many years after its publication, it makes a striking impression both because of the author's penetrating analysis and of the technical standard of the problem treatment.

In a series of later works Segerdahl applied risk theory to practical problems of insurance, both life and non-life. His duties as actuary in Thule up to I947 and later on in other companies put him in close touch with the practical work of an insurance business, which has enriched both the theory and its practical applications. One may entirely agree with Grenander that among researchers within collective risk theory, Segerdahl has acquired a profile of his own by paying great attention to the real possibilities for practical application of the theory.

More recently, Segerdahl wrote about non-homogeneous stochastic processes and about even more general processes, as defined by. Khintchine, with continuous and discontinuous components. $\mathrm{He}$ took up and developed the so-called renewal processes presented by the Danish mathematician, Sparre Andersen, at the Actuarial Congress in New York in I957.

Segerdahl's achievements were not merely limited to applying mathematical models to the insurance business. As statistician at "Radiumhemmet" in Stockholm, for example, he collaborated with professors Heyman and Kottmeier in a number of monographs which analyzed the results of radiotherapy on the treatment of cervical cancer, etc.

Segerdahl had an unusually versatile mind with a rarely developed theoretical and practical inventiveness. His suggestions and ideas were often brilliant, but could at times seem naive, and inevitably, his many interests were bound to split his personality. His contributions to research and its applications could have become even more valuable, if he had not had too many irons in the fire.

Beginning in I95I Segerdahl was affiliated with Stockholm University as "docent" or professor pro tem. in the chair occupied by Cramér and later Grenander. In December, I970, Segerdahl was appointed professor of Actuarial Mathematics and Mathematical Statistics at Stockholm University. It did not befall him to discharge the duties of this new post for very long. With his 6oth birthday 
just ahead, he passed away after slightly more than one year of office.

As co-editor of the Scandinavian Actuarial Journal from I 940 and as editor-in-chief from I964, Segerdahl assumed a central position in the research concerned with Actuarial Mathematics. From this platform he was given abundant opportunities to keep up with literature in this field and also to develop his own profile in relation to other investigators. The editing of a leading international periodical in the domain of mathematical statistics involves great demands on the editorial staff. Segerdahl also dealt with the practical tasks entirely by himself. It was unavoidable that many subscribers showed impatience when delays arose, delays that the editorial staff could not overcome, mainly on account of difficulties in connection with printing.

Within the ASTIN circle Segerdahl's achievements were, of course, highly appreciated. Thanks to his theoretical and practical gifts as well as his vast experience, he gave proof of common sense far removed from airy visions. One of his valuable contributions was rendered to the ASTIN meeting at Rättvik in I96r. Many of us will remember him from the ASTIN meeting at Randers in I970, when, with verve and personal commitment, he dealt with the subject, "Risk theory, in particular the overall risk involved in operating an insurance concern".

Before then he had been actively engaged in promoting the symposium on risk theory which the Filip Lundberg Foundation held in the spring of 1968 . He was also enabled to edit papers for the symposium in a supplement to the Scandinavian Actuarial Journal (I969, 3-4), which appeared in the summer of 1970.

The memory of Carl Otto Segerdahl's genius and great talents also hold the image of a well trained yachtsman, of a connoisseur of flowers and of a nature lover. Further, we shall remember him as an unaffected and helpful friend.

Ove LUNDBERG 